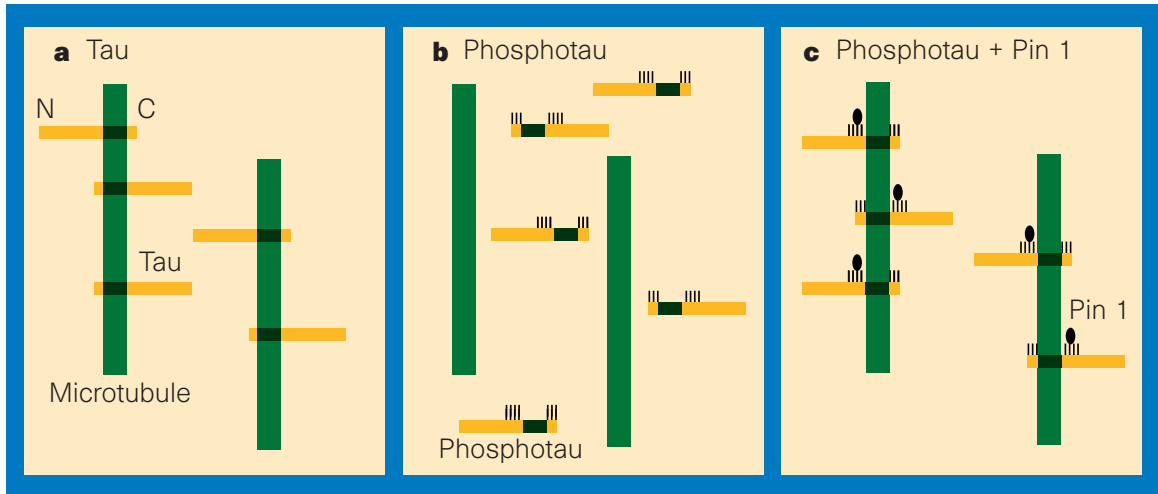

Figure 1 Pin1 restores the ability of phosphorylated tau to bind to microtubules. a, Nonphosphorylated tau protein (yellow) binds to microtubules (green). b, Cdc2 kinase phosphorylates tau at a number of sites where serine or threonine precedes a proline residue (S/T-P sites), located on either side of the microtubule-binding repeats (shown in black). As a result, tau has a reduced ability to bind to microtubules. c, The work of Lu et al. ${ }^{1}$ indicates that Pin 1 (ovals) binds to phosphorylated tau protein and restores its ability to bind to microtubules. Pin1, by itself, does not bind to microtubules. Phosphothreonine 231 in tau is both necessary and sufficient for the interaction with Pin1. The isomerase activity of Pin1 is required to restore the biological activity of phosphorylated tau.

phorylated tau was restored, an effect that seemed to depend on Pin1's prolyl isomerase activity. This surprising result indicates that isomerization of the peptide bond on the amino-terminal side of proline residue 232 in tau is enough to confer biological activity upon Cdc2-phosphorylated tau. Moreover, it suggests that the same may be true of the hyperphosphorylated tau in Alzheimer's disease. However, Cdc2 kinase phosphorylates only some of the residues that are hyperphosphorylated in the disease, and it remains to be seen whether Pin 1 could restore the biological activity of tau in vivo.

Lu et al. next compared the levels of soluble Pin 1 in the brains of Alzheimer's patients with those in age-matched control brains. By immunoblotting and immunoprecipitation, they saw greatly reduced levels of soluble Pin 1 in the diseased brain. The most striking abnormality of tau in Alzheimer's disease is its assembly into filaments, and these results indicate that tau filaments may sequester soluble Pin1. Depletion of Pin1 in nonneuronal cells leads to mitotic arrest ${ }^{2}$, so the observed depletion may have been related to ectopic expression of some cell-cycle markers in the brains of people with Alzheimer's disease ${ }^{15-17}$. The significance of this observation for the neurodegenerative process is unclear, although it has been suggested that aberrant expression of cell-cycle markers may cause nerve cell death by apoptosis.

The identification of mutations in the tau gene should allow us to study these questions more rigorously. Using such mutants, it has already been shown that a reduced ability of tau to interact with microtubules may precede hyperphosphorylation and assembly into filaments ${ }^{14}$. So, compounds that reduce the pool of functionally impaired tau could be of therapeutic value. The discovery of the interaction between Pin 1 and phosphorylat- ed tau may open the way to developing such compounds.

Michel Goedert is at the MRC Laboratory of

Molecular Biology, Hills Road, Cambridge

CB2 2QH, UK.

e-mail:mg@mrc-lmb.cam.ac.uk

1. Lu, P.-J., Wulf, G., Zhou, X. Z., Davies, P. \& Lu, K. P. Nature 399, 784-788 (1999)

2. Lu, K. P., Hanes, S. D. \& Hunter, T. Nature 380, 544-547 (1996). 3. Yaffe, M. B. et al. Science 278, 1957-1960 (1997).

4. Vincent, I., Rosado, P. \& Davies, P. J. Cell Biol. 132, 413-425 (1996).

5. Kondratick, C. M. \& Vandré, D. D. J. Neurochem. 67, 2405-2416 (1996).

6. Pope, W. B. et al. Exp. Neurol. 126, 185-194 (1994).

7. Illenberger, S. et al. Mol. Biol. Cell 9, 1495-1512 (1998).

8. Hasegawa, M. et al. J. Biol. Chem. 267, 17047-17054 (1992).

9. Watanabe, A. et al. J. Biol. Chem. 268, 25712-25717 (1993).

10. Ishiguro, K. et al. FEBS Lett. 325, 167-172 (1993).

11. Goedert, M. et al. Biochem. J. 301, 871-877 (1994).

12. Matsuo, E. S. et al. Neuron 13, 989-1002 (1994).

13. Morishima-Kawashima, M. et al. J. Biol. Chem. 270, 823-829 (1995).

14. Goedert, M., Crowther, R. A. \& Spillantini, M. G. Neuron 21, 955-958 (1998)

15. Vincent, I., Jicha, G., Rosado, M. \& Dickson, D. W. J. Neurosci. $17,3588-3598$ (1997).

16. Nagy, Zs., Esiri, M. M., Cato, A.-M. \& Smith, A. D. Acta Neuropathol. 94, 6-15 (1997).

17. Busser, J., Geldmacher, D. S. \& Herrup, K. J. Neurosci. 18, 2801-2807 (1998)

erratum In Stefan Rahmstorf's News and Views article "Shifting seas in the greenhouse?" (Nature 399, 523-524; 1999), the last five references were incorrectly numbered in the reference list. The correct numbering is:

10. Oppenheimer, M. Nature 393, 325-332 (1998).

11. Boer, G. J., Flato, G. M. \& Ramsden, D. Clim. Dyn. (submitted). 12. Hirst, A. C., Gordon, H. B. \& O'Farrell, S. P. Geophys. Res. Lett 23, 3361-3364 (1996).

13. Knutson, T. R., Delworth, T. L., Dixon, K. \& Stouffer, R. J. J. Geophys. Res. (submitted)

14. Hegerl, G. et al. Clim. Dyn. 13, 631-634 (1997).
Daedalus

Metallic compost

All iron rusts in the end. Indeed, rapid rusting would be an ideal way of getting rid of old iron objects and structures. Rusting is a solid-state combustion; it absorbs oxygen and gives out heat - a reaction exploited in some heat-packs. So, says Daedalus, would an iron nail in an insulated oxygen flask get hotter and hotter as rusting started and speeded up, until it ultimately melted? Alas, no. Rusting is an electrolytic reaction, and needs liquid water. Once the temperature reaches $100^{\circ} \mathrm{C}$, rusting must stop.

But imagine a flask sealed and pressurized to 15 bar. Water inside it will remain liquid above $100^{\circ} \mathrm{C}$. At 15 bar it will reach $200^{\circ} \mathrm{C}$ - at which a new rusting reaction starts to occur, one which works not only with water but with steam. Iron starts to reduce water directly, without oxygen, giving heat, rust and hydrogen. So an insulated scrap-iron dump, pressurized to 15 bar would, as it heated itself above $200^{\circ} \mathrm{C}$, and began to boil, would start to liberate this most ecologically virtuous of fuels. The temperature might even rise to the melting-point of iron.

So Daedalus's 'ferrous compost heap' is a large vertical cylinder, vacuum-insulated and with counter-current heat exchangers to feed the heat of its outputs back into its inputs. Iron scrap is fed into the top, and slowly descends into the increasingly hotter depths. Tappings at its base extract molten iron and iron oxide - the latter, of course, is high-grade iron ore. Air and steam are fed in at appropriate points, hydrogen and residual gases are extracted at others. It will be self-heating and selfmaintaining.

At first Daedalus saw his ferrous compost heap as a simple disposer for old cans, car-bodies, oil drums and scrap metal too dirty, rusty or contaminated for normal recovery. But he now wonders what will happen to organic dirt and waste mixed in with the metal. A conventional incinerator oxidizes organic waste to steam, carbon dioxide and various pollutants. But iron is a strong reducing agent and (thanks to its variable valency) a versatile catalyst. It should reduce organic waste, perhaps to liquid or gaseous hydrocarbons or alcohols, useful fuels and solvents. Fed with a judicious mixture of old iron and general organic garbage, the ferrous compost heap should turn these nuisances into a range of handy fuels and raw materials, giving out heat but no pollution. Ecologists and industrialists alike would be delighted.

David Jones 


\section{Shifting seas in the greenhouse?}

Stefan Rahmstorf

\section{Models of the Earth's possible responses to global warming are continually being improved. The latest simulation of changes in deep flow in the Atlantic operates without several of the fudge factors previously required.}

$\mathrm{T}$ he effect that global warming might have on the circulation of the Atlantic Ocean has been a topic of much speculation and research. On page 572 of this issue, Wood et al. ${ }^{1}$ present greenhouse warming scenarios computed with a climate model that, for the first time, gives a realistic simulation of the large-scale ocean currents without requiring artificial adjustments of the air-sea fluxes.

Of more immediate interest to those outside the modelling business, Wood and colleagues' results show a dramatic change in the Atlantic occurring over the next few decades: a complete shutdown of one of the two main 'pumps' driving the formation of North Atlantic Deep Water, namely the one in the Labrador Sea (Fig. 1).

In 1987, in an article entitled "Unpleasant surprises in the greenhouse?", Broecker ${ }^{2}$ warned that the response of the climate system to greenhouse warming might involve 'mode switches' of the Atlantic circulation. He drew this inference from palaeoclimatic data, indicating that such events had occurred in the past, and from early ocean modelling results. Initially, the idea was simply that a positive feedback meant that the large-scale overturning motion of the Atlantic (sometimes popularly dubbed the 'conveyor belt', in which warm surface waters flow northwards and cold deep water returns south throughout the Atlantic, acting like a central-heating system for Europe; see Fig. 1) could exist in two distinct states - switched on (as at present) or switched off.

Later work revealed a more complex picture, by showing that individual sites of oceanic convection could also have a tendency towards flip-flop behaviour (switching between quasi-stable states with convection 'on' or 'off') $)^{3,4}$. Given that there are two main sites of convection linked to the formation of North Atlantic Deep Water, in the Greenland Sea and in the Labrador Sea, this led to speculation that global warming could switch off one of these convection sites 5 .

Wood et al. ${ }^{1}$ provide the first clear modelling result indicating that this could indeed be the response to increasing concentrations of greenhouse gases. The team works at the Hadley Centre in Britain, and their climate model is remarkable in several respects. Cer- tain improvements, including a higher resolution of the ocean and parameterizations of eddy mixing and of the flow of bottom currents over marine sills, mean that the model provides a more realistic representation of the main ocean currents than previous coupled ocean-atmosphere models. In particular, the partitioning of the deep-water formation between the Greenland and Labrador Seas is in good agreement with observations. Furthermore, unlike most previous climate models, this model does not use or require 'flux adjustments' at the air-sea interface, which involve adding a prescribed heat or freshwater flux to make up for a mismatch between ocean and atmosphere components of the climate model. Flux adjustments had to be used in the past to prevent the model climate from drifting slowly to unrealistic conditions, but they may distort the stability of the ocean circulation ${ }^{6}$.

The authors subject their model to two greenhouse-gas scenarios: an artificially rapid increase in atmospheric concentrations by $2 \%$ per year up to a quadrupling of $\mathrm{CO}_{2}$, and a more realistic 'business as usual' scenario starting in 1860 and extending to the year 2100. In both cases, the overall volume of water transported by the Atlantic conveyor belt (Atlantic overturning) decreases by around $25 \%$, but it does not reach the point of collapse. This is consistent

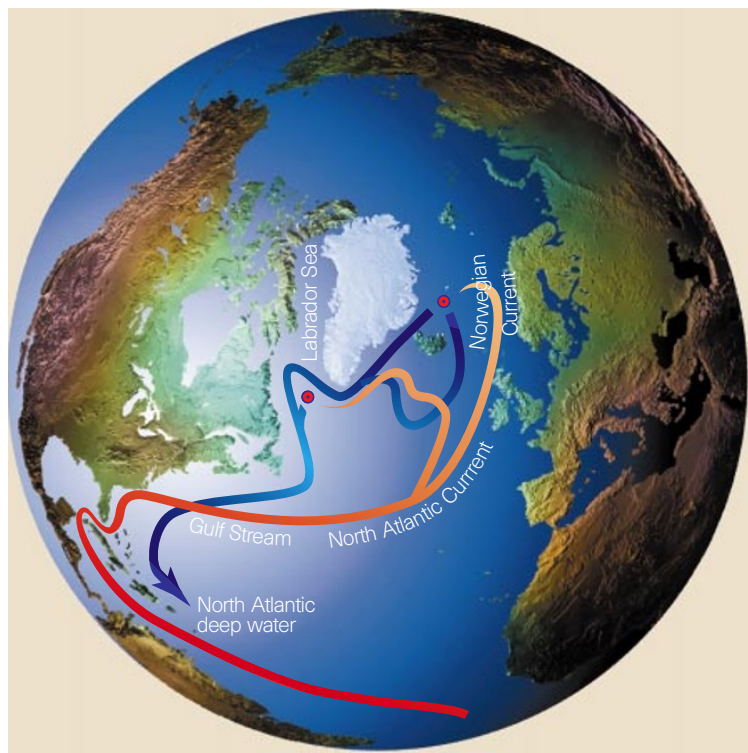

Figure 1 Simplified sketch of currents in the North Atlantic, showing the two main convection sites in the Greenland and Labrador Seas. Warm surface currents are shown in red; cold, deep currents in blue. Red-andblue circles, convection sites. 


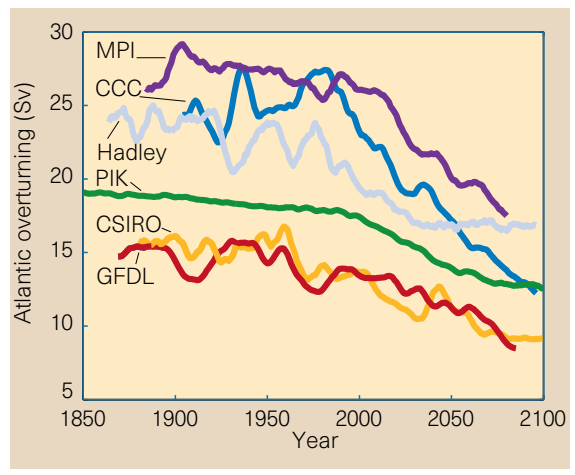

Figure 2 Simulated water-volume transport of the Atlantic 'conveyor belt' (Atlantic overturning) in a range of global warming scenarios computed by different climate research centres. Units are Sverdrups, $10^{6} \mathrm{~m}^{3} \mathrm{~s}^{-1}$. Although a wide range of transport is simulated for the unperturbed climate, all of the models generally show little change up to the present. But all show a significant weakening of the flow in the next century as a result of greenhouse warming. Data shown are nine-year running mean values. CCC, Canadian Centre for Climate Modelling and Analysis, Victoria ${ }^{11}$. CSIRO, Division of Atmospheric Research, Melbourne ${ }^{12}$. GFDL, R30 model of the Geophysical Fluid Dynamics Laboratory, Princeton (ensemble of three runs) ${ }^{13}$. Hadley, HadCM3 model of the Hadley Centre, Bracknell, UK ${ }^{1}$. MPI, ECHAM3/LSG model of the Max Planck Institute for Meteorology, Hamburg ${ }^{14}$. PIK, CLIMBER-2 model of the Potsdam Institute for Climate Impact Research ${ }^{7}$.

warming, as the input of fresh water from increased precipitation would have a considerable effect on oceanic convection by changing the surface water density. Different models of atmospheric behaviour predict widely differing changes in precipitation. The Hadley Centre model also does not take into account the fresh water entering the Labrador Sea from the north, through the Canadian archipelago.

Given these uncertainties, the results of Wood et al. should be interpreted as a warning that a regional shut-down of convection could occur and that it could even occur soon, without taking the specific timing and location as a definitive prediction. The Labrador convection site may indeed be more vulnerable to greenhouse warming than the Greenland Sea site, given that the deep water formed in the Labrador Sea is already the less dense of the two, which could mean that a relatively small reduction in surface density could stop convection altogether. This hypothesis needs to be confirmed by future modelling studies.

So far, however, observations show no sign of a systematic weakening of convection in the Labrador Sea. On the contrary, after a weak phase in the late 1960s, convection in the 1990s has been favoured by the high phase of the North Atlantic Oscillation ${ }^{8}$, the dominant mode of natural variability in the region. Both North Atlantic convection regions need to be continuously monitored, as planned in the international CLIVAR (Climate Variability and Predictability) programme.

The simulated ending of Labrador Sea convection found in the Hadley Centre model is perhaps the most convincing demonstration so far of a qualitative threshold being crossed because of global warming. Such nonlinear effects are increasingly receiving attention in climate research, following the 1995 IPCC report's ${ }^{9}$ warning that "future climate change may also involve 'surprises". Another possible 'surprise' (the term is a misnomer, as the element of surprise lessens the more it is discussed) is that the West Antarctic Ice Sheet could become unstable and slide into the ocean, causing sea level to rise by several metres ${ }^{10}$.

To evaluate the risk of such events it is not enough to compute a few 'best guess' projections of future climate change. More sophisticated and systematic approaches to risk assessment are required, taking the full range of uncertainty in current knowledge and models into account. This is a difficult task, not helped by the fact that many climate models operate at the limits of available computer power. Nevertheless, it needs to be tackled. As in any risk assessment, it is not just the most likely outcome of global warming that affects how we should handle the problem, but also the 'tail ends' of the probability distribution of possible futures: events with a low probability but a high damage potential. Take the risk of nuclear power stations for comparison: the most likely scenario is that everything works just fine, but large investments are nevertheless made to insure against the tiny probablilty of a catastrophic failure.

Although many global warming risks are still difficult to quantify, the work of Wood and colleagues is a reminder that now is the time to invest in a 'full-cover insurance policy' by reducing greenhouse gas emissions. $\square$ Stefan Rahmstorf is at the Potsdam Institute for Climate Impact Research (PIK), PO Box 6012 03, 14412 Potsdam, Germany.

e-mail:stefan@pik-potsdam.de

1. Wood, R. A., Keen, A. B., Mitchell, J. F. B. \& Gregory, J. M. Nature 399, 572-575 (1999).

2. Broecker, W. Nature 328, 123-126 (1987).

3. Lenderink, G. \& Haarsma, R. J. J. Phys. Oceanogr. 24, 1480-1493 (1994).

Rahmstorf, S. Nature 378, 145-149 (1995).

5. Rahmstorf, S. Nature 388, 825-826 (1997).

6. Marotzke, J. \& Stone, P. H. J. Phys. Oceanogr. 25, 1350-1364 (1995)

7. Rahmstorf, S. \& Ganopolski, A. Clim. Change (in the press).

8. Dickson, B. Nature 386, 649-650 (1997).

9. Houghton, J. T. et al. (eds) Climate Change 1995: The Science of Climate Change (Cambridge Univ. Press, 1996).

10. Hirst, A. C., Gordon, H. B. \& O'Farrell, S. P. Geophys. Res. Lett. 23, 3361-3364 (1996).

11. Knutson, T. R., Delworth, T. L., Dixon, K. \& Stouffer, R. J.

J. Geophys. Res. (submitted).

12. Hegerl, G. et al. Clim. Dyn. 13, 631-634 (1997).

13. Oppenheimer, M. Nature 393, 325-332 (1998).

14. Boer, G. J., Flato, G. M. \& Ramsden, D. Clim. Dyn. (submitted).

Antibiotic resistance

\section{A vancomycin surprise}

Michael S. Gilmore and James A. Hoch

V ancomycin is the last line of defence against organisms such as Streptococcus pneumoniae and Enterococcus, some strains of which are resistant to most other antibiotics. Whereas $S$. pneumoniae is responsible for diseases such as pneumonia, meningitis and otitus media (ear infection), Enterococcus bacteria cause many hospitalacquired infections. Because pneumococcal pneumonia alone results in over a million deaths each year worldwide ${ }^{1}$, any compromise in our ability to treat these infections is an important public-health concern. In just ten years, vancomycin resistance has spread among the enterococci from one initial observation to the situation now, where $52 \%$ of clinical E. faecium isolates are resistant ${ }^{2}$. This rapid spread seems to be due, in part, to an association between resistance to vancomycin and resistance to penicillin and ampicillin ${ }^{2}$. On page 590 of this issue, Novak and colleagues ${ }^{3}$ report a new threat to antibiotic therapy - the emergence of penicillinresistant clinical isolates of $S$. pneumoniae, which are also tolerant to a number of other antibiotics, including vancomycin.
Tolerance and resistance are somewhat different. Whereas antibiotic-resistant microorganisms are insensitive to the antibiotic, and continue to grow in its presence, the antibiotic-tolerant strains stop growing but do not die in the presence of the antibiotic. In neither case does antibiotic therapy eliminate the infective agent, meaning that the infection can continue once therapy is curtailed. Antibiotic tolerance is particularly insidious because it cannot be detected using conventional in vitro tests - tolerant strains seem to be sensitive to antibiotics.

Novak et al. ${ }^{3}$ now show that roughly $3 \%$ of the clinical S. pneumoniae isolates they studied were tolerant to antibiotics. Streptococcus pneumoniae is the most common cause of bacterial meningitis in the United States, with the infection most prevalent among the very young and the very old ${ }^{4}$. Antibiotic-tolerant strains of the bacterium are most likely to cause problems at places where the body's immune response is limited, such as in the brain (meningitis) or the eyes (intraocular infection). Consistent with this proposal, the authors show that multi- 